Retraction

\title{
Retracted: Oxygen Mass Transfer in an Aerated Stirred Tank with Double Impellers: A Generalized Correlation Including Spacing Impact
}

\section{International Journal of Chemical Engineering}

Received 9 April 2017; Accepted 9 April 2017; Published 11 May 2017

Copyright (c) 2017 International Journal of Chemical Engineering. This is an open access article distributed under the Creative Commons Attribution License, which permits unrestricted use, distribution, and reproduction in any medium, provided the original work is properly cited.

At the request of the author, the article titled "Oxygen Mass Transfer in an Aerated Stirred Tank with Double Impellers: A Generalized Correlation Including Spacing Impact" [1] has been retracted. The data presented in the article were published without the permission of the University of Toulouse.

\section{References}

[1] H. M. Issa, "Oxygen Mass Transfer in an Aerated Stirred Tank with Double Impellers: A Generalized Correlation Including Spacing Impact," International Journal of Chemical Engineering, vol. 2016, Article ID 7386453, 2016. 


\title{
Oxygen Mass Transfer in an Aerated Stirred Tank with Double Impellers: A Generalized Correlation Including Spacing Impact
}

\author{
Hayder Mohammed Issa \\ College of Engineering, University of Salahaddin-Erbil, Erbil, Iraq \\ Correspondence should be addressed to Hayder Mohammed Issa; hayder.issa@su.edu.krd
}

Received 4 December 2015; Accepted 12 January 2016

Academic Editor: Dmitry Murzin

Copyright (c) 2016 Hayder Mohammed Issa. This is an open access article distributed under the Creative Commons Attribution License, which permits unrestricted use, distribution, and reproduction in any medium, provided the original work is properly cited.

Stirred aerated tanks by double impellers are used in fermentation and various biological processes for water treatment, food industry, and pharmaceutical production. In this study, a generalized correlation model was developed for the dependent parameter $\left(k_{1} a / N\right)$. The oxygen mass transfer from air to liquid takes place by rotating the double impellers (IBRC and PBPU) in the aerated tank. This model considers Reynolds number, Froude number, power number, the liquid height, and the spacing between impellers as the most significant specifications that are related to aerated tank performance. The spacing between the impellers is considered to be a design factor of such industrial equipment due to its remarkable impact on the oxygen mass transfer.

\section{Introduction}

Stirred tanks that generate a turbulent fluid flow regime are commonly used for aeration in various industrial processes like aerobic fermentation and wastewater treatment to obtain a complete oxygen mass transfer [1]. The oxygen mass transfer in an aerated tank actually takes place in two zones: the liquid surface and liquid body. At the liquid surface, there are two types of oxygen transfer: firstly, the direct transfer of oxygen to the liquid surface due to large eddies created by impeller rotation and, secondly, the oxygen transfer by the contact of projected water droplets with air, while the oxygen mass transfer inside the liquid body occurs mainly by the entrained air bubbles from the surface [2]. As it is so difficult and complicated to determine the surface mass transfer coefficient individually because there are no exact limits between these two zones. The final oxygen mass transfer in the liquid body is considered to be the total liquid side oxygen mass transfer. Hence, the dissolved oxygen inside the liquid body would refer to the total dissolved oxygen that came from any mass transfer pattern, above, at, and below the liquid surface.

The occurring oxygen transfer mechanism in the entirely liquid (water) body is the two-film theory [3]. The oxygen transfer in the water body is related to many parameters, such as water level, tank and impeller geometry, rotation speed, the number of impellers, and many operational conditions [4-6].

The theory of oxygen transfer in the surface aerated tank is relevant to the mixing that occurs within the tank. Therefore, mixing is improved by adding extra impellers at the rotating shaft to enhance the contact area between liquid (water) and air phases [7]. As the effective resistance to the oxygen mass transfer that takes place mainly exists in the liquid side of the gas-liquid mass transfer film, other resistance is neglected. Oxygen mass transfer coefficient in the liquid, $k_{l} a$, is regarded as an indicator for mass transfer rate [8]. The gas-liquid contact interfacial area for oxygen mass transfer is highly crucial in the rational design of gas-liquid equipment [9]. The volumetric oxygen mass transfer in liquid phase $k_{l} a$ is determined by a dynamic method for batch systems. Many tries were made to find a generalized correlation for oxygen mass transfer in surface aerators. There were various trends to correlate the relevant parameters with the oxygen transfer coefficient. Fuchs et al. [10] have proposed a correlation of $k_{l} a$ with energy dissipation in the liquid body $(P / V)$ for surface aerators tank volume $(V \geq 200 \mathrm{~L})$. The influence of tank and impellers geometry has been related in many correlations with oxygen transfer models. Zlokarnik [11] has correlated the oxygen mass transfer for various surface aerator geometries. 
He has developed a generalized oxygen mass transfer parameter, as a dimensionless parameter $(Y)$ that called sorption number $\left(Y=k_{l} a D^{3}\left(\mu / \rho g^{2}\right)^{1 / 3}=\left(G / \Delta c \cdot D^{3}\right) \cdot\left(v / g^{2}\right)^{1 / 3}\right)$, where, in his model, he related the surface flow characteristics and turbulence intensity with the transferred oxygen. Zlokarnik [11] has additionally related the mass transfer performance with the operational parameters such as Froude number, Reynolds number, and other geometrical factors (numbers and forms of impellers blades). He has derived a dimensionless formulation that combines the surface aerator efficiency $(E)$ with aeration number and Froude number with $(Y)$, for the ratio liquid to turbine diameter ratio $(h / D)$ of 1.0:

$$
E=\frac{G}{\Delta c D^{3}}\left(\frac{v}{g^{2}}\right)^{1 / 3} N_{p}^{-1} \mathrm{Fr}^{-3 / 2}=\frac{G D^{0.5}}{P \Delta c} \rho\left(v^{2} g^{5}\right)^{1 / 6},
$$

where $\Delta c$ is concentration difference $\left(\mathrm{kg} \mathrm{m}^{-3}\right), G$ is oxygen uptake $\left(\mathrm{kgO}_{2} \mathrm{~h}^{-1}\right)$, and $E$ is aerator efficiency $\left(\mathrm{kgO}_{2} \mathrm{~kW}^{-1} \mathrm{~h}^{-1}\right)$.

Patil et al. [12] have tested different surface aerators for optimum $k_{l} a$ with emphasis on the geometrical configuration; the affecting parameters they considered were liquid height, liquid volume, tank diameter, and impeller clearance. They derived a general correlation of oxygen mass transfer in depending upon the previous works in the same field for aeration, operation condition, and power consumption. The range of volumetric power consumption dissipation was $90<$ $P / V<400 \mathrm{~W} / \mathrm{m}^{3}$ :

$$
\frac{k_{l} a}{N}=7 \times 10^{-6} N_{p}^{0.71} \operatorname{Fr}^{0.48} \operatorname{Re}^{0.82}\left(\frac{H}{D}\right)^{-0.54}\left(\frac{V}{D^{3}}\right)^{-1.08} .
$$

Thakre et al. [13] have developed an oxygen transfer model for curved rotor surface aerator in oxidation ditches after they studied the liquid level effect. The model is applied for turbulent flow condition and $S / D$ ratio between 0.17 and 0.25 :

$$
k_{l} a=0.000746\left[(N)^{1.768}\left(\frac{H}{D}\right)^{1.038}(\alpha)^{0.031}\right]
$$

where $\alpha$ is the blade tip angle.

Various attempts were made to correlate the oxygen transfer for diverse affecting variables in aeration process. These attempts were made by depending on the proposed relevant geometric, material, and process parameters [14-18].

The aim of this study is to develop an oxygen mass transfer model in the dual impellers gas-liquid (aerated) system showing the effects of the flow pattern, power consumption, spacing between the two impellers, and liquid height. This model of oxygen mass transfer with the relevant factors has not been studied in previous works till now for surface aerated tanks.

\section{Materials and Methodology}

A digital dissolved oxygen probe was used in the experimental runs. The dissolved oxygen measurement was achieved depending on the oxygen partial pressure with correction for the affecting factors such as the temperature. Concentration units are expressed in milligrams of oxygen per liter of water $(\mathrm{mg} / \mathrm{L})$. An average percentage error of the probes readings was calculated by least squares best fit between experimental and theoretical readings. Average percentage error was $3.49 \%$.

During the aeration process, the mass transfer is mostly from the water surface to the inside of the liquid body. The principals of oxygen mass transfer depend on the resistance to the oxygen mass transfer, which occurs in the liquid phase. So the oxygen mass transfer coefficient in the gas phase is neglected. Before each test, the initial concentration of dissolved oxygen should be set close to zero and then water was saturated by direct contact with air [22].

The implemented calculation for the oxygen mass transfer $\left(k_{l} a\right)$ based on several general assumptions: the vessel is efficiently mixed; $k_{l} a$ values throughout the vessel can be represented as one value. Furthermore, the saturated dissolved oxygen can be represented as one value. It was assumed that no other mass transfer occurs during the operation for the other constituents, similarly for the used nitrogen gas during the deoxygenation process. Weak heat gradient occurred during the aeration; in that manner the accompanied heat transfer was ignored.

The response time for the used probe was determined by depending upon both the experimental and theoretical results of dissolved oxygen. The theoretical values of the dissolved oxygen are determined by $[23,24]$

$$
C_{t}=C_{s}-\left(C_{s}-C_{o}\right) e^{-t / \tau}
$$

The $\tau$, response time, was determined for the dissolved oxygen probe and was $8.8 \mathrm{sec}$.

The relationship between the dissolved oxygen with the time with taking in account the effect of probe response time can be represented in the following equation [25-27]:

$$
\frac{d C_{l}}{d t}=k_{l} a\left(C_{s}-C_{l}\right) \text {. }
$$

By rearranging,

$$
\ln \frac{\left(C_{s}-C_{t}\right)}{\left(C_{s}-C_{0}\right)}=k_{l} a \cdot t
$$

The effect of probe response time on the dissolved oxygen concentration measurement for aeration processes was determined by the following equation [28]:

$$
C_{t}=C_{s}+\frac{C_{s}-C_{t}}{C_{s}-C_{0}}\left(k_{l} a \cdot \tau e^{-t / \tau}-e^{-k_{l} a t}\right) .
$$

The dissolved oxygen probe response time was implied in the applied mass transfer equation that represents the experimental runs to take into account the experimental errors. It is needed to correct the measured oxygen transfer coefficient in the liquid to the standard conditions, where the following (Van't-Hoff, Arrhenius) equation was applied [29]:

$$
\left(k_{l} a\right)_{20^{\circ} \mathrm{C}}=1.024^{(20-\theta)}\left(k_{l} a\right)_{\theta} \text {. }
$$


The experimental runs were carried out in a cylindrical flat bottom vessel (made of transparent fiberglass) with inside diameter of $0.8 \mathrm{~m}$. The schematic diagram of the system is shown in Figure 1. Three baffles of width, $b(0.1 T)$, are used with our experimentation, to prevent or lessen the tangential circulatory flow. The baffles have the same height of the vessel.

The surface aeration is attained by the water droplets projection with the rotation of an impeller and by the water surface renewal due to eddies generation. In the experimentation, two impellers (IBRC + PBPU) were used for mixing and aeration purposes with the up-pumping operation, where the rotating cone (IBRC) was placed at the water surface. To achieve acceptable mixing that provides a good contact interfacial area between the contents, the lower four-bladed propeller (PBPU) redirects the liquid flow toward the upper rotating cone (IBRC) to ensure continuous feeding intake of the rotating cone. Moreover, the propeller (PBPU) participates in achievement of the homogenous distribution of dissolved oxygen in the entire vessel by ensuring the flow circulation through the whole vessel especially the deep good levels.

The geometrical ratio for the propeller $(d / T)=0.15$, where it is lower than the general applied ratio $(d / T)$ for axial flow impellers (0.2-0.7). In our study the aim of the mixing process is supporting the main surface aeration process, so the desired mixing performance was performed. The number of blades of the rotating cone is 12 (blades width $0.24 \mathrm{~m}$ ), with diameter ratio $D / T=0.24$. Water height was kept constant at $0.38 T$.

To figure the most affecting limits during the operation, various parameters are considered to be independent variables to relate to the oxygen mass transfer, where the important aim is to verify and improve, through the experimentation, the effect of spacing with the oxygen transferred.

In the experimental part, the relationship between $k_{l} a$ with power consumption, rotation speed $(N=1.67-5.0 \mathrm{rps})$, and liquid level $(H / D=1.37-1.45)$ was conducted for three spacing levels between the used impellers $(S / d=0.5,0.75,1)$.

\section{Oxygen Mass Transfer Correlation Model}

In this study, an oxygen mass transfer model was developed depending on the experimental results made by [30] and the previously performed studies. Normally in surface aeration process there are geometric, dynamic, and materials parameters that govern the system performance. These parameters may involve the rotational speed, the water viscosity, the gravity of acceleration, the impeller diameter (these parameters may refer to the intensity of turbulence inside the tank and at the water surface), the water height in the tank, and many others. The number of these parameters is different according to each case, but generally they are the same essential parameters that work for all the surface aeration cases. The Froude number Fr reflects the gravitational acceleration force and the water wave action generated by the aerator. The Reynolds number Re refers to flow state of the liquid. The power number $N_{p}$ indicates the power consumed by the aerator considering the aerated fluid property. Finally

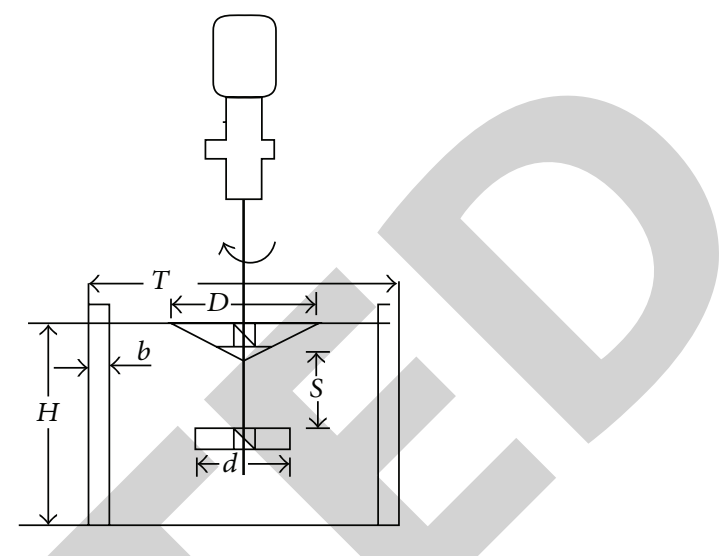

FIGURE 1: The schematic diagram of the experimental setup.

the mass transfer dimensionless parameter forms (it is not restricted to use of one normalized mass transfer parameter, but it depends on the system distinction implemented). In accordance with experimental results, it is found that the most realistic independent variables that can affect the oxygen transfer are as follows:

$$
\left(k_{l} a\right)=f(N, P, \rho, \mu, D, S, H, g) .
$$

The geometric ratios are chosen upon the standard design ratios that are generally implied in the surface aeration process.

By applying Buckingham $\pi$ theory, (9) converted to the following relation:

$$
\left(\frac{k_{l} a}{N}\right)=f\left[\begin{array}{llll}
N_{p}^{a} & \operatorname{Re}^{b} & \operatorname{Fr}^{c} & \left(\frac{H}{D}\right)^{d}\left(\frac{S}{D}\right)^{e}
\end{array}\right],
$$

where $a, b, c, d$, and $e$ are constants (varying).

Since the surface aeration process is predominantly within the turbulent flow state, Reynolds number can be ignored, where for air-water submergence aerator the value of Re is always $\left(>10^{4}\right)$, so the Re is considered irrelevant to the process objective [11].

So (10) is reformed as

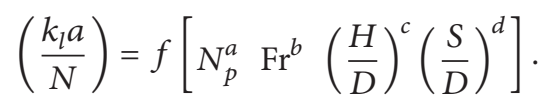

Equation (11) is solved to determine the values of the constants by applying multiple nonlinear regressions. The following correlation is developed:

$$
\begin{aligned}
& \left(\frac{k_{l} a}{N}\right) \\
& \quad=0.0121\left[N_{p}^{1.05} \mathrm{Fr}^{1.435}\left(\frac{H}{D}\right)^{-1.786}\left(\frac{S}{D}\right)^{-0.564}\right] .
\end{aligned}
$$

Here, the standard error for the constants in (12) is as follows: for $(f)$ a standard error is $3.79 * 10^{-2}$, for $(a)$ the standard error is $1.07 * 10^{-2}$, for $(b)$ the standard error is $7.39 * 10^{-3}$, for (c) the standard error is $7.49 * 10^{-2}$, and for $(d)$ the standard 
TABLE 1: The most commonly stated oxygen mass transfer coefficient correlations for stirred and aerated vessels with multiple impellers (liquid volume of $0.036-0.46 \mathrm{~m}^{3}$ ).

\begin{tabular}{|c|c|}
\hline $\begin{array}{l}\text { System } \\
\text { description }\end{array}$ & Correlation \\
\hline $\begin{array}{l}T=0.8 \mathrm{~m} \\
D / T=0.24 \\
N=1.67-5.0 \mathrm{rps} \\
H / D=1.37-1.45 \\
S / d=0.5-1.0 \\
\text { IBRC-PBPU } \\
\text { Air-water }\end{array}$ & $\left(\frac{k_{l} a}{N}\right)=0.0121\left[N_{p}^{1.05} \operatorname{Fr}^{1.435}\left(\frac{H}{D}\right)^{-1.786}\left(\frac{S}{D}\right)^{-0.564}\right]$ \\
\hline $\begin{array}{l}T=0.6 \mathrm{~m} \\
D / T=0.33 \\
H / T=1-3 \\
N=2.5-10 \mathrm{rps} \\
\text { Various multiple impeller } \\
\text { Air -water }\end{array}$ & $k_{l} a=3.69 \times 10^{-3}\left(P_{\mathrm{tot}}^{n}\right)^{0.601} U_{S}^{0.375}\left(\frac{P_{g}}{P_{0}}\right)^{0.521} N_{p}^{0.068}$ \\
\hline $\begin{array}{l}T=0.3 \mathrm{~m} \\
D / T=0.4 \\
H / T=1.8 \\
N=8-13 \mathrm{rps} \\
\text { PDT + 2CBYN } \\
\text { Air-water }\end{array}$ & Zhang et al. 2015 [20] \\
\hline $\begin{array}{l}T=0.2 \mathrm{~m} \\
D / T=0.5 \\
H / T=0.8-1.8 \\
N=1-10 \mathrm{rps} \\
\text { LSB multiple impeller } \\
\text { Pure } \mathrm{O}_{2} \text {-water }\end{array}$ & $k_{l} a=0.0346$ \\
\hline
\end{tabular}

error is $3.71 * 10^{-2}$. The mass transfer correlation (12) is applicable for the three ranges, $\left(P / V\right.$, watt $\left./ \mathrm{m}^{3}\right)=(22-100)$, $(N, \mathrm{rps})=(1.67-3.33)$, and $(H / D)=(1.37-1.45)$.

Equation (12) gives acceptable predictions for oxygen mass transfer dimensionless parameter $\left(k_{l} a / N\right)$ with a coefficient of determination $\left(R^{2}\right)$ of 0.988 when compared with the actual experimental results (see Figure 2).

Many correlations were developed to predict oxygen mass transfer coefficient $k_{l} a$ in aerated and stirred tanks without showing the impact of the spacing between the used impellers as the correlation that was developed in this work. The predicted values for the $k_{l} a$ coefficient for a variety of different vessels and impellers geometries are listed in Table 1. Table 1 shows the $k_{l} a$ values for the most commonly stated correlations that have been developed according to different relevant parameters. With comparing the developed correlation in this work with most commonly reported correlations for multiple impellers in aerated and stirred tanks, all give reasonable prediction for $k_{l} a$ results. Average deviations are $5.2 \%, 14 \%$, and $5.2 \%$ for the correlations developed in this work, by Moucha et al. [19] and by Luo et al. [21], respectively, whilst Zhang et al. [20] pointed out that their correlation has a coefficient of determination of 0.984 .

\section{Conclusion}

The comparison of the predicted values by applying correlation with experimental results values shows that the coefficient of determination is 0.988 , which is accepted in the

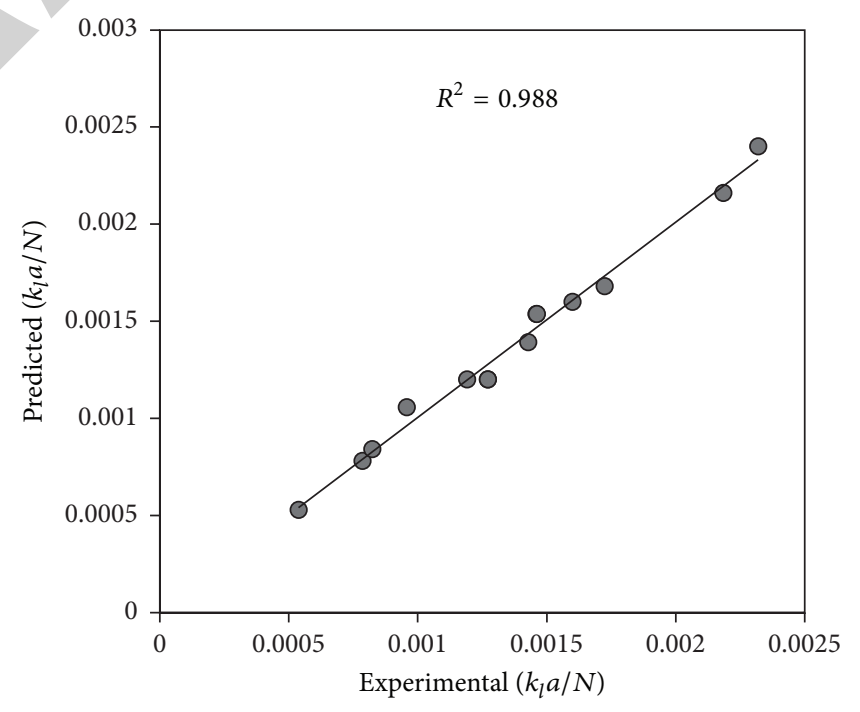

FIGURE 2: Comparison between the $\left(k_{l} a / N\right)$ values predicted by the correlation (12) with the experimentally resulting $\left(k_{l} a / N\right)$ values (each point in the figure represents four results at the same tested condition).

frame of the error estimation (see Figure 2). The correlation model is developed for gas-liquid oxygen mass transfer coefficient in stirred tank with double impellers (with spacing effect) showing acceptable results for specified operational and geometrical ranges. 


\section{Symbols}

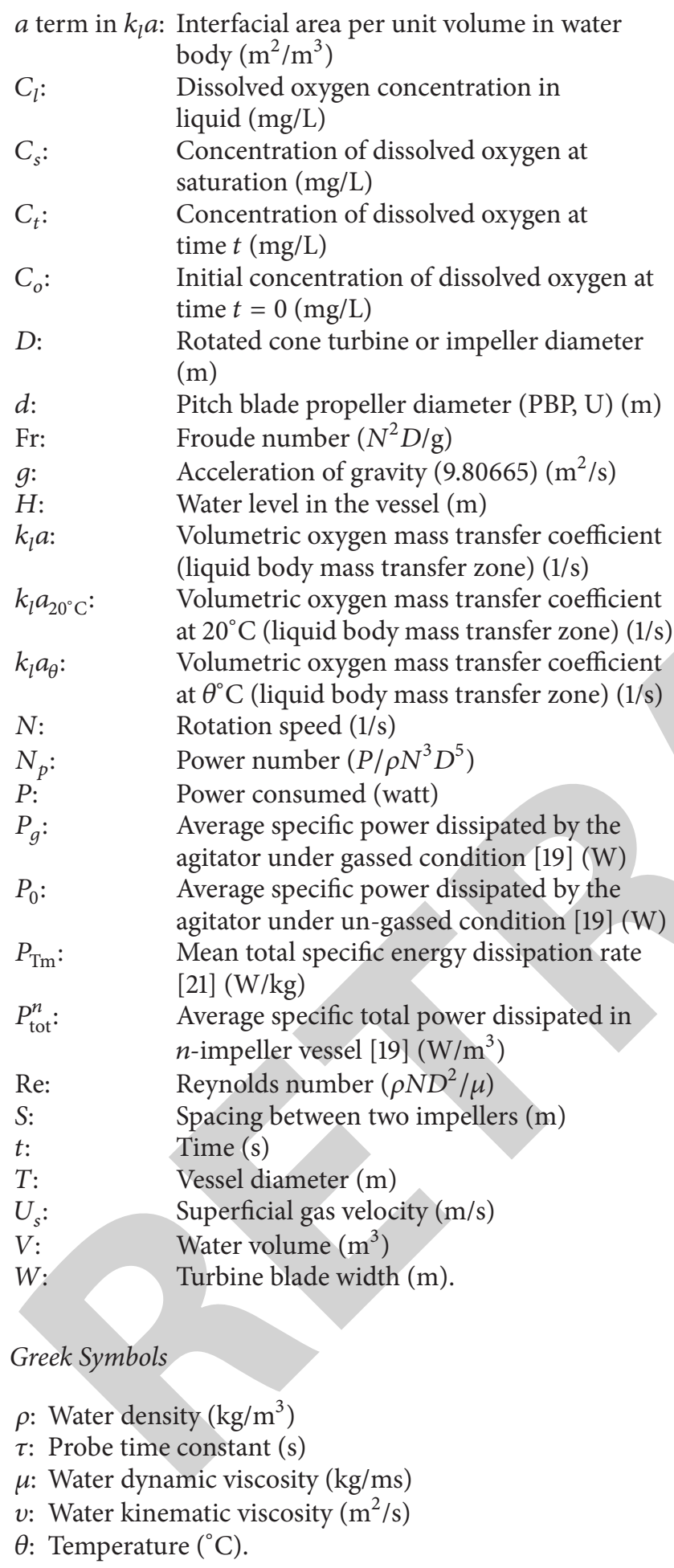

\section{Impellers Types Abbreviations}

IBRC: Inverted pitched rotated cone (developed particularly for surface aeration), up-pumping

PBP, U: Pitch blade propeller, up-pumping

PDT: Parabolic-blade disk turbine [21]
CBYN: CBY narrow blade [21]

LSB: Long-short blades (LSB) agitator [20].

\section{Conflict of Interests}

The author declares that there is no conflict of interests regarding the publication of this paper.

\section{References}

[1] T. Devi and B. Kumar, "Design of a gas-liquid unbaffled stirred tank with a concave blade impeller," Journal of Engineering Physics and Thermophysics, vol. 88, no. 1, pp. 76-87, 2015.

[2] J. R. McWhirter, J.-M. Chern, and J. C. Hutter, "Oxygen mass transfer fundamentals of surface aerators," Industrial \& Engineering Chemistry Research, vol. 34, no. 8, pp. 2644-2654, 1995.

[3] J. F. Atkinson, S. Blair, S. Taylor, and U. Ghosh, "Surface aeration," Journal of Environmental Engineering, vol. 121, no. 1, pp. 113-118, 1995.

[4] R. Yatomi, K. Takenaka, K. Takahashi, and P. Tanguy, "Masstransfer characteristics by surface aeration of large paddle impeller: application to a polymerization reactor with liquid level change," Chemical Engineering Research and Design, vol. 86, pp. 1345-1349, 2008.

[5] C. Bandaiphet and P. Prasertsan, "Effect of aeration and agitation rates and scale-up on oxygen transfer coefficient, $k_{\mathrm{L}}$ a in exopolysaccharide production from Enterobacter cloacae WD7," Carbohydrate Polymers, vol. 66, no. 2, pp. 216-228, 2006.

[6] M. Nakanoh and F. Yoshida, "Gas absorption by Newtonian and non-Newtonian liquids in a bubble column," Industrial \& Engineering Chemistry Process Design and Development, vol. 19, no. 1, pp. 190-195, 1980.

[7] K. Van't Riet, "Review of measuring methods and results in nonviscous gas-liquid mass transfer in stirred vessels," Industrial and Engineering Chemistry Process Design and Development, vol. 18, no. 3, pp. 357-364, 1979.

[8] V. Schlüter and W.-D. Deckwer, "Gas/liquid mass transfer in stirred vessels," Chemical Engineering Science, vol. 47, no. 9-11, pp. 2357-2362, 1992.

[9] A. M. Dehkordi and C. Savari, "Determination of interfacial area and overall volumetric mass-transfer coefficient in a novel type of two impinging streams reactor by chemical method," Industrial and Engineering Chemistry Research, vol. 50, no. 10, pp. 6426-6435, 2011.

[10] R. Fuchs, D. D. Y. Ryu, and A. E. Humphrey, "Effect of surface aeration on scale-up procedures for fermentation processes," Industrial \& Engineering Chemistry Process Design and Development, vol. 10, no. 2, pp. 190-196, 1971.

[11] M. Zlokarnik, "Scale-up of surface aerators for waste water treatment," in Advances in Biochemical Engineering, vol. 11 of Advances in Biochemical Engineering/Biotechnology, pp. 157180, Springer, Berlin, Germany, 1979.

[12] S. S. Patil, N. A. Deshmukh, and J. B. Joshi, "Mass-transfer characteristics of surface aerators and gas-inducing impellers," Industrial \& Engineering Chemistry Research, vol. 43, no. 11, pp. 2765-2774, 2004.

[13] S. B. Thakre, L. B. Bhuyar, and S. J. Deshmukh, "Oxidation ditch process using curved blade rotor as aerator," International Journal of Environmental Science and Technology, vol. 6, no. 1, pp. 113-122, 2009. 
[14] B. Kumar and A. R. Rao, "Oxygen transfer and energy dissipation rate in surface aerator," Bioresource Technology, vol. 100, no. 11, pp. 2886-2888, 2009.

[15] Y. Chisti and U. J. Jauregui-Haza, "Oxygen transfer and mixing in mechanically agitated airlift bioreactors," Biochemical Engineering Journal, vol. 10, no. 2, pp. 143-153, 2002.

[16] K. Chandrasekharan and P. H. Calderbank, "Further observations on the scale-up of aerated mixing vessels," Chemical Engineering Science, vol. 36, no. 5, pp. 818-823, 1981.

[17] S. Moulick, B. C. Mal, and S. Bandyopadhyay, "Prediction of aeration performance of paddle wheel aerators," Aquacultural Engineering, vol. 25, no. 4, pp. 217-237, 2002.

[18] N. A. Deshmukh and J. B. Joshi, "Surface aerators: power number, mass transfer coefficient, gas hold up profiles and flow patterns," Chemical Engineering Research and Design, vol. 84, no. 11, pp. 977-992, 2006.

[19] T. Moucha, V. Linek, K. Erokhin, J. F. Rejl, and M. Fujasová, "Improved power and mass transfer correlations for design and scale-up of multi-impeller gas-liquid contactors," Chemical Engineering Science, vol. 64, no. 3, pp. 598-604, 2009.

[20] J. Zhang, Z. Gao, Y. Cai, Z. Cai, and Y. Bao, "Mass transfer in gas-liquid stirred reactor with various triple-impeller combinations," Chinese Journal of Chemical Engineering, 2015.

[21] P. Luo, J. Wu, X. Pan, Y. Zhang, and H. Wu, "Gas-liquid mass transfer behavior in a surface-aerated vessel stirred by a novel long-short blades agitator," AIChE Journal, 2015.

[22] S. A. El-Temtamy, S. A. Khalil, A. A. Nour-El-Din, and A. Gaber, "Oxygen mass transfer in a bubble column bioreactor containing lysed yeast suspensions," Applied Microbiology and Biotechnology, vol. 19, no. 6, pp. 376-381, 1984.

[23] J. C. Merchuk, S. Yona, M. H. Siegel, and A. B. Zvi, "On the first-order approximation to the response of dissolved oxygen electrodes for dynamic $k_{\mathrm{L}}$ a estimation," Biotechnology and Bioengineering, vol. 35, no. 11, pp. 1161-1163, 1990.

[24] J. A. Mueller, W. C. Boyle, and E. N. Lightfoot, "Effect of the response time of a dissolved oxygen probe on the oxygen uptake rate," Applied Microbiology, vol. 15, no. 3, pp. 674-676, 1967.

[25] M. S. Puthli, V. K. Rathod, and A. B. Pandit, "Gas-liquid mass transfer studies with triple impeller system on a laboratory scale bioreactor," Biochemical Engineering Journal, vol. 23, no. 1, pp. 25-30, 2005.

[26] S. J. Arjunwadkar, K. Sarvanan, P. R. Kulkarni, and A. B. Pandit, "Gas-liquid mass transfer in dual impeller bioreactor," Biochemical Engineering Journal, vol. 1, no. 2, pp. 99-106, 1998.

[27] J.-M. Chern and S.-P. Yang, "Oxygen transfer rate in a coarsebubble diffused aeration system," Industrial and Engineering Chemistry Research, vol. 42, no. 25, pp. 6653-6660, 2003.

[28] R. Sardeing, M. Poux, S. Melen, P. Avrillier, and C. Xuereb, "Aeration of large size tanks by a surface agitator," Chemical Engineering \& Technology, vol. 28, no. 5, pp. 587-595, 2005.

[29] S. Capela, S. Gillot, and A. Héduit, "Comparison of oxygentransfer measurement methods under process condition," Water Environment Research, vol. 76, no. 2, pp. 183-188, 2004.

[30] H. M. Issa, Characterization and improvement of a surface aerator for water treatment [Ph.D. thesis], Université Toulouse III, Toulouse, France, 2013. 